\title{
Sağlık Yönetiminde Hasta Memnuniyeti: Bir Devlet Hastanesi Örneği
}

\author{
DOI: $10.26466 /$ opus.872579
}

*

\author{
Elçin Güven* \\ ${ }^{*}$ Dr, Ersin İnanç Mali Müşavirlik A.Ş, Kırklareli/Türkiye \\ E-Posta: elcinguven@windowslive.com ORCID: 0000-0003-0920-0861 \\ Öz
}

Sağllk yönetimi, nitelikli insan gücünün yetiştirilmesi, halk sağhlğının geliştirilmesi, sağhlk hizmetlerinin kaliteli ve verimli olması için gün geçtikçe önem kazanmaktadır. Sağlık yönetiminin en önemli unsurlarından biri, hasta memnuniyetidir. Hasta memnuniyeti, hastaların; hekiminden, să̆glk çalışanlarından ve uygulanan tedaviden memnun kalmasıdır. Hasta memnuniyeti kavramı 1960'larda ortaya çıkmış, 1980'li yıllarda ilgi odağı haline gelmiştir. Hasta memnuniyetini etkileyen faktörlerden bazıları; hastalara tedavi süreçleriyle ilgili gerekli bilgilerin verilmesi, sağlık hizmeti veren çalışanların davranış ve tutumları, zamanlama ve fiyattır. Son yıllarda sağ lık yönetimi ve sağllk hizmetleri ile ilgili değerlendirmelerde, hasta memnuniyeti, mevcut kaynakların doğru kullanımı ve karar aşamasında gerekli kanıt olarak görülmektedir. Bu çalışmada, sağlık yönetimi, hasta memnuniyeti ele alınmıştır ve Kırklareli ilinde bulunan bir devlet hastanesinde anket çalışması yapılmıştır. Bu çalışmanın amacı, sağlık yönetimine ve hizmetlerine ilişkin memnuniyet değerlendirmeleri kapsamında, Kırklareli ilinde bulunan hastanelerden birinde anket çalışması yapılmıştır. Araştırma bulguları; sağlık kurumunda memnuniyet temelinde 100 hemşire ile yüz yüze anket yöntemi uygulanarak gerçekleştirilmiş ve değerlendirilmiştir.

Anahtar Kelimeler: Sağlık Yönetimi, Sağlık Sistemi, Hasta Memnuniyeti 


\title{
Patient Satisfaction in Health Care Management: An Example of Public Hospital
}

\begin{abstract}
Health care management has been gaining significance gradually day by day in respect to training qualified workforce, improving public health care services so that such services are performed by highly qualified staff efficiently and effectively by all means. One of the most significant factors of health care management is satisfaction of patients. Patient satisfaction means patients are satisfied with the services of doctors, healthcare professionals and the procedures of heath care practices. The concept of patient satisfaction first emerged in 1960s and became a trending topic in 1980s. Some factors with an impact on patient satisfaction includes providing the patients with sufficient information and required documentation on treatment processes, behaviors and attitudes of health professionals as well as timing and pricing. For recent analysis on medical management and medical services, patient satisfaction is considered as a necessary evidence for the right use of resources and for making the right decisions. A questionnaire study was conducted in a public hospital located in Kirklareli Province and health care management as well as patient satisfaction was dealt within the framework of this research. The aim of this study is to examine and reveal patient satisfaction rates within the content of evaluation of those people's satisfaction in regard to health care services management as well as the services performed in one the public hospitals located in Kurklareli Province by conducting a questionnaire research study at site. Research findings were compiled on the basis of retail questionnaire method by having interviews with 100 nurses at site and those obtained findings have been assessed accordingly.
\end{abstract}

Keywords: Health Care Management, Health Care System, Satisfaction of Patient 


\section{Giriş}

1980'lerden itibaren ekonomik krizlerle savaşan gelişmekte olan ülkelerin bütçelerinde büyük payı olan sağlık bütçesi, yaşanan krizlerden olumsuz etkilendi (Çağlayaner, 2008, s.55). Sağlık sektörü, son elli yılda, büyüme trendi içinde, gelişme potansiyeli olan bir sektördür. Sağlığın her alanında kullanılan kaynaklar, toplumsal refah için kullanılan kaynakların önemli kısmını oluşturmaktadır (Mutlu ve Işık, 2012, s.1). Grup çalışmaları veya bireysel çalışmaların, ortak amacı gerçekleştirmek için yaptıkları faaliyetlere yönetim denir (Tengilimoğlu vd., 2012, s.33). İşletme yönetiminin yaşanan gelişmelerle beraber, sosyal sistem içinde önemi arttı (Can ve İbicioğlu, 2008, s.254). Genel yönetimden sağlık yönetimine geçildiğinde, sağlık yönetimi; tıbbi bakım ve sağlık hizmetlerinin, kişilere, toplumlara sunulması için, kaynakların planlanması, örgütlenmesi, yönlendirilmesi, kontrolu olarak tanımlanmaktadır (Çimen, 2010, s.136). Memnuniyet, yaşam şekli, kişilerin deneyimleri ve beklentileri, bireysel ve toplumsal değerleri içeren pek çok faktör ile bağlantılı bir kavramdır. Sağlık hizmetlerinin sonuçlarının algılanması ve beklentilerin karşılanması ile ilişkili olan hasta memnuniyeti, farklı kişilerce, farklı zamanlarda farklı şekilde tanımlanabilmektedir (Zaim ve Tarım, 2010, s.9). Hasta memnuniyeti; hasta, hekim ve sağlık yönetimi ve hizmetlerinden oluşmaktadır. Hasta memnuniyetinin ölçümü: hasta ve yakınlarının beklentileri, geri bildirimlerinin değerlendirilmesi, değerlendirilen sonuçları kapsamaktadır (Dinç vd., 2009, s.93). Hasta memnuniyetinin artırılması için, hasta tatminini etkileyen ölçütler olarak hijyen, ilgi, teknolojik alt yapı gibi hizmetin fiziksel özelliklerinin yanı sıra, gereksinim duyulduğunda ulaşlabilen, uygun fiyatta ve uygun kalitede olma kriterleri de göz önünde bulundurulmalıdır. Hastaların, sağlık hizmetleriyle ilgili beklentilerini etkileyen dört unsur aşağıdadır:

- Hastanın tibbi gereksinimleri,

- Diğer sağlik kurumlarından elde edilen deneyimler,

- Sosyo-kültürel ve psikolojik durumları,

- Hastaların kalite tanımı

Sağlık kuruluşlarının hasta memnuniyetini artırmak için, sağlık hizmet kalitesinin iki temel değişkenini ön plana çıkarmaları gerekmektedir.

a. Modern tıbbi-tedavi hizmetlerinin gerektirdiği optimal sağlık hizmetinin verilmesi,

b. Hasta hak, istek ve beklentilerinin karşılanması (Tükel vd., 2004:206). 
Bu çalışma, sağlık yönetimi, hasta memnuniyeti ve Kırklareli ilinde bulunan bir devlet hastanesinde yapılan anket çalışmasından oluşmaktadır.

\section{Sağlık Yönetimi}

Toplum ve birey sağlığının iyileştirilmesi, korunması için sağlık alanında yapılan organizasyon ve faaliyetlere sağlık yönetimi denir. Etkili sağlık yönetimi, yüksek performanslı bir sağlık hizmeti sunum sistemi ve stratejik yönetimin oluşturulması ile gerçekleşir (Linnander vd., 2017, s.555). Sağlık yönetiminde, yöneticilerin yeterli ve profesyonel hizmet verebilmeleri için gerekli donanıma ve tecrübeye sahip olmaları gerekmektedir (Stewart ve Wolvaardt, 2019, s.6). Sağllk yönetiminde, ülkelerde, farklılıklar görülmektedir. Örneğin; Amerika'da başlangıçta sağlık kurumları, kurum sahipleri olan hekimler tarafından yönetilirken, daha sonra sağlık yöneticilerine bu işin bırakıldığı fakat son yıllarda hekimlerin yeniden sağlık yönetiminde rol almaya başladığ görülmektedir (Hayran, 2012, s.88). Sağlık alanında da, yönetim, sağlık işletmelerinin temelidir. Etkin yönetimin önemi, sağlık hizmetlerinin sunumunun profesyonel olması, kaliteli olması, sağlık çalışanlarının verimli çalışması, tüm hizmet sürecinin etkin şekilde ilerlemesi, sağlık yönetiminde önemi arttırmaktadır. Toplumda ihtiyacı olan insanlara, sağlık hizmetlerinin ulaştırılması için, sağlık alanında yönetim ekibinin görevlerini yerine getirmesi gerekmektedir. Dünyada ve Türkiye'de nüfusun sürekli artısı, sağlık hizmetlerine ulaşma, faydalanma olanaklarının artmasıyla birlikte sağlık yönetimi büyük önem kazanmaktadır. Sağllk yönetimine verilen önemin artması, sağlık hizmet kalitesini artmasını sağlamaktadır. Sağlık çalışanlarının desteklenmesi ve denetlenmesinde yönetim rol almaktadır. Sağlık çalışanlarının çalışma performanslarının değerlendirilmesi sonucunda, performanslarında artış olması için stratejiler belirlenebilir. Bu stratejiler, etkin performans değerlendirme sistemi aracılığı ile olur. Bu aşamaların gerçekleşmesinde yönetimin etkinliği önemlidir (Ürün, 2019, s.46). Sağllk yönetiminde önemli unsurlar, kalite, verilen hizmetlerde sürdürülebilirlik, bilgilendirme, hastane gelişimi, tıbbi maliyetlerin kontrolüdür ( Luo ve Gao, 2017, s.1). Sağlık bakımı ile ilgili organizasyon aşamaları, yönetim metotlarına uyumlu olmak zorundadır (Ginter vd., 2018, s.10). Sağllk yönetimi, modern toplumlarda, önemli bir disiplindir. Bu disiplin, klinik hizmet ve servis hizmet sunumlarının kali- 
teli olması, sunulan sağlık hizmetlerine hızlı erişimin sağlanması, ileri teknolojik cihazların hastalıkların tespitinde kullanılması, önemli süreçleri içeren yönetim anlayışını zorunlu hale getirmektedir. Sağlıkta profesyonel yönetim anlayışı, sağlık yöneticilerinin niteliklerinin önemini etkilemektedir (Akdaş vd., 2008, s.1). Ayrıca, sağlık sisteminde ve yönetiminde en önemli bileşen karar destek entegrasyonudur. Elektronik sağlık kayıtlarındaki iyileştirmelerin yönetime katkıları çoktur ( Stacy ve Adam, 2019, s.2). Sağlıkla ilgili problemlerin çözümü için, dünyada ve Türkiye'deki sağlık çevrelerinde, sağlık yönetiminin işlevleri önemlidir. Sağlık personeli ve tıbbi teknolojik gereçlerin yetersizliği, sağlık göstergelerindeki olumsuzlukların temelinde, kötü sağlık yönetiminin rol aldığı bilinmektedir. Günümüzde bu nedenlerle; sağlık sigortasıyla birlikte sağlığa talepteki artış, sağlık sektöründeki yeniliklerin meydana gelmesi, sağlık harcamalarının artmasının nedenidir. Sağlık sektöründe kaynakların etkin kullanımı ve büyüklüğü, sağlık hizmetlerinin performansının artması amacının oluşumuna sebep olmaktadır. Sağlık hizmetlerinin hızlı sunulması ve ulaşılabilir olması gerekmektedir. Sağlıkta yönetim unsuru, tüm bunların meydana gelmesi için, önemli hale gelmiştir. Sağlık yönetimi işi, gelişmiş toplumlarda, yönetim alanları, arasında en zor olanlardan biri olarak kabul görmekle birlikte, sağlık kurumlarının yönetim kadrosunda profesyonel yöneticilerin olması gereklidir. Ayrıca; sağlık yönetiminde karar verme, yönetici statüsündeki hekim veya sağlık çalışanları tarafından paylaşlmasıyla, alınan kararların sadece yönetici statüsünde olanlar tarafından alınması doğru değildir. Sağlık yönetiminde kararlar alınırken tüm çalışanların karar aşamasına katılımının sağlanması, uygulanabilirliği arttıracaktır (Yorulmaz, 2015, s.16-17). Sağlık hizmetlerinde rekabetin hızla artması, global dünyada, sağlık yönetiminin önemini arttırmıştır. Ekonomik büyümenin önemli unsurlarından biri olan, sağlık alanında yaşanan gelişmeler, sağlık kuruluşlarını ve dolayısıyla sağlık yönetimini kaliteli, ulaşılabilir, hizmet sunmaya yönlendirmektedir (Kara, 2018, s.53).

Sağlık personelinin hastalarla olan iletişimi ve davranışları alınan sağlık hizmetinin memnuniyetini etkilemektedir. Tarih boyunca, hekim-hasta ilişkisi farklı şekillerdeydi. Geçmişte hasta-hekim arasındaki ilişki, hekimin tek başına yönlendirdiği bir ilişkiydi fakat zamanla, yol gösterici ilişkiye dönüşmüştür. Hekim ve hasta arasındaki ilişkide en temel faktör teşhis ve tedavi sürecinin etkililiğidir. İlişki sürecinde hastanın istekleri, şikâyetleri, hastalıkla 
ilgili korkuları belirlenir. Hekim-hasta arasındaki ilişkide, memnuniyet, verilen sağlık hizmetinin başarısı için gereklidir. Teşhis ve tedavinin başarılı şekilde yapılması için hekim-hasta arasında şeffaflık, karşılıklı güven esası olması gerekmektedir. Bu süreçte hastanın hekimlere teşhis ve tedavide tam olarak güvenmesi gereklidir (Gezergün vd., 2006, s.130). Sağlık kuruluşlarının en önemli amacı, hasta memnuniyetidir. Hasta memnuniyeti, bir kalite ölçüsü değil, sağlık hizmeti sunumunun amacıdır (Zavare, 2010, s.118). Hasta memnuniyeti, sağlık hizmetlerinin sürdürebilirliğinde önemli bir faktördür (Faezipoura ve Ferreira, 2019, s.149).

Hasta memnuniyeti; sağllk hizmeti almaya karar vermesinden itibaren, başlayan tüm süreçleri içeren beklenti ve faydaların karşılaştırılmasıyla elde edilen sonuçtur. Başka bir tanıma göre; hasta memnuniyeti, hastaların istek ve beklentilerinin karşılanma oranıdır. Hasta memnuniyetini etkileyen faktörler; hastalara gerekli bilgilerin verilmesi, çevresel-fiziksel koşullar, sağlık hizmeti veren çalışanların davranış ve tutumları, zamanlama ve fiyattır (Kılıç ve Topuz, 2015, s.82). Hasta memnuniyeti, sağlık hizmetlerinin kalitesinin önemli bir ölçüsüdür. Hasta memnuniyeti ve memnuniyetsizliği önemli sonuçlar doğurmaktadır (Xesfingi ve Vozikis, 2016, s.1-2). Sağlık hizmetlerinde, müşteri memnuniyetinin karşıllğı hasta memnuniyetidir. Sağlıkta kalitenin en önemli göstergelerinden biri hasta memnuniyetidir. Son yıllarda sağlık yönetimi ve sağlık hizmetleri ile ilgili değerlendirmelerde, hasta memnuniyeti, mevcut kaynakların doğru kullanımı ve karar aşamasında gerekli kanıt olarak ifade edilmektedir (Akçakanat ve Çarıkçı, 2019, s.60). Hasta memnuniyeti kavramı 1960'larda ortaya çıkmıştır. 1980'li yıllarda ilgi odağı haline gelen hasta memnuniyeti ile ilgili çalışmalarda son yıllarda artış vardır. 1970'lerde sağlık alanına tüketici davranışlarının yansımasıyla, rekabetin artması ve kaliteli sağlık hizmet beklentisinin yaygınlaşmasıyla önemli hale gelmiştir. Hasta memnuniyeti kavramı, hizmetin performansını, faydasını, maliyetini ve sunumunu içerir. Sağlık personeli ve hekimle iletişimin önemi, uygun tedavinin uygulanması, sağlık hizmetinden memnuniyeti sağlayan önemli etkenlerdir. Memnuniyet sağlik hizmetlerinin tüm basamaklarında en önemli unsurlardan biridir (Dinç vd., 2009, s.94). Hasta memnuniyet araştırmalarında amaç, hastaların aldıkları hizmetin kalitesini değerlendirmesi, hastaların memnuniyetlerini etkileyen unsurların belirlenmesi, kurumu tercih nedenleri ve aldıkları hizmetten beklentileri, hizmet sunum sürecinde yaşanan olumsuzluklar ve hizmet sunum şeklinin hastaların beklentileri karşılayacak 
şekilde tasarlanması şeklinde değerlendirilmesi gerekmektedir (Yılmaz, 2001:72-73). Hasta memnuniyeti modelinde aşağıdaki maddeler bulunmaktadır: (Hawthorne vd., 2014, s.528)

- Sağlık hizmetlerine uygun erişim, tedavinin gerçekleştiği ortam ve bakım koordinasyon düzeyi

- Hastaların sağlık bilgilerinin sağlanması

- Hasta ve sağlik personeli arasındaki ilişki

- Uygun tedavinin yapilıp doğru ilaç tedavisinin uygulanması (Hawthorne vd., 2014, s.528).

Hasta memnuniyeti sağlık kurumlarında hizmet kalitesini değerlendirmede kullanılan temel bir ölçüt olup hastaların sosyo-demografik özellikleri ve tedavi sürecine ilişkin faktörlerden etkilenmektedir (Taşlıyan ve Akyüz, 2010:62). Hasta memnuniyeti çalışmalarının çoğu, zaman içindeki deneyimlerinden ziyade hastaların tek seferlik karşılaşmalardaki deneyimlerine dayanmaktadır (Thiedke, 2007, s.33).

\section{Yöntem}

Anket formunun hazırlanmasında; literatür tarama sonucu elde edilen dokümanlardan, Anadolu Üniversitesi, Sosyal Bilimler Enstitüsü, Çalışma Ekonomisi ve Endüstri İlişkileri Anabilim Dalı Doktora öğrencisi Emre KOL’UN “Türkiye'de Sağlık Hizmetlerinde Yaşanan Dönüşüm: Eskişehir'de Alt Gelir Grupları Üzerine Bir İnceleme" tezinde kullandığı anket formundan yararlanılmıştır. Gerekli değişiklikler yapılarak son şekli verilmiş ve yüz yüze anket yöntemiyle 6 soru sorularak 100 hemşireye uygulanmıştır. 19 Şubat ve 29 Şubat 2019 tarihleri arasında Kırklareli İl Sağlık Müdürlügü̈nden resmi izin alınarak, Kırklareli ilinde bulunan devlet hastanelerden birinde yapılmıştır.

SPPS 25 (IBM Corp. Released 2017. IBMSPSS Statistics for Windows, Version 25.0. Armonk, NY: IBM Corp.) istatistik programı ile veriler değerlendirildi. Değişkenlerde, frekans değerleri ve yüzde değerleri kullanılmıştır. Kategorik veriler, Ki Kare testi ve Fisher's Exact Test ile analiz edilmiştir. "Monte CarloSimulasyon Yöntemi" ile değerlendirme yapılmasının amacı, beklenen frekansların \% 20'den küçük olmasıdır. Testlerin anlamlılık düzeyi için $\mathrm{p}<0,05$ ve $\mathrm{p}<0,01$ değeri kabul edilmiştir. 


\section{Bulgular}

Tablo 1. Çalışmaya Katılan Hemşirelerin Tanıtıcı İstatistikler

\begin{tabular}{|c|c|c|c|}
\hline & & $\mathrm{n}$ & $\%$ \\
\hline \multirow{4}{*}{ Yaş } & $18-25$ & 30 & 30,0 \\
\hline & $26-39$ & 29 & 29,0 \\
\hline & $40-59$ & 25 & 25,0 \\
\hline & $60+$ & 16 & 16,0 \\
\hline \multirow{2}{*}{ Cinsiyet } & Kadın & 53 & 53,0 \\
\hline & Erkek & 47 & 47,0 \\
\hline \multirow{5}{*}{ Öğrenim Durumu } & İlkokul & 15 & 15,0 \\
\hline & Ortaokul & 17 & 17,0 \\
\hline & Lise Mezunu & 24 & 24,0 \\
\hline & Yüksekokul/Fakülte & 40 & 40,0 \\
\hline & Yüksek Lisans/Doktora & 4 & 4,0 \\
\hline \multirow{2}{*}{$\begin{array}{l}\text { Hastanedeki Yönetimden Ve Sağlık Sisteminin İşleyi- } \\
\text { şinden Memnun musunuz? }\end{array}$} & Evet & 55 & 55,0 \\
\hline & Hayır & 45 & 45,0 \\
\hline \multirow{3}{*}{$\begin{array}{l}\text { Hastanelerin Hepsine Ücretsiz Gidebilme İmkânınız } \\
\text { Olsaydı Hangi Hastaneyi Tercih Ederdiniz? }\end{array}$} & Kamu hastaneleri & 23 & 23,0 \\
\hline & Özel Hastaneler & 48 & 48,0 \\
\hline & Üniversite Hastaneleri & 29 & 29,0 \\
\hline \multirow{4}{*}{ En Sık Hangi Sağlık Kurumuna Gitmektesiniz? } & Devlet hastanesi & 49 & 49,0 \\
\hline & Sağlık Ocağ1 & 23 & 23,0 \\
\hline & Özel hastaneler & 22 & 22,0 \\
\hline & Üniversite hastaneleri & 6 & 6,0 \\
\hline \multirow{2}{*}{$\begin{array}{l}\text { Devlet Hastanelerine Randevu Alınarak Gidilmesi İle } \\
\text { Sağlık Hizmetlerine Daha Kolay Ulaşılmaktadır? }\end{array}$} & Evet & 78 & 78,0 \\
\hline & Hayır & 22 & 22,0 \\
\hline \multirow{2}{*}{$\begin{array}{l}\text { Devlet Hastanelerine Randevu Alınarak Gidilmesi İle } \\
\text { Sağlık Hizmetlerinin Kalitesi Arttırılmıştır? }\end{array}$} & Evet & 66 & 66,0 \\
\hline & Hayır & 34 & 34,0 \\
\hline \multirow{3}{*}{$\begin{array}{l}\text { Devlet Hastanelerine Randevu Alınarak Gidildiği İçin } \\
\text { Doktorlar Sağlık Sorunlanıma Daha Fazla Zaman Ayır- } \\
\text { maktadır? }\end{array}$} & Evet & 45 & 45,0 \\
\hline & Hayır & 55 & 55,0 \\
\hline & Toplam & 100 & 100,0 \\
\hline
\end{tabular}

Ankete katılanların \% 53'ü kadın, \% 47'si erkektir. \% 15'i ilkokul, \%17'si ortaokul, \%24'ü lise, \% 40'i fakülte, \% 4'ü yüksek lisans/doktora mezunudur. Ankette hastanedeki yönetimden ve sağlık sisteminin işleyişinden memnun musunuz? sorusuna \% 55 evet, \%45 hayır demiştir. Hastanelerin hepsine ücretsiz gidebilme imkânınız olsaydı hangi hastaneyi tercih ederdiniz? sorusuna \%23'ü kamu hastanesi, \% 48'i özel hastane, \%29'u özel hastane olarak cevaplamıştır.

En sık hangi sağlık kurumuna gitmektesiniz? Sorusuna \% 49'u devlet hastanesi, \% 23'ü sağlık ocağı, \% 22'si özel hastane, \% 6's1 üniversite hastanesini tercih etmiştir. Devlet hastanelerine randevu alınarak gidilmesi ile sağlık hizmetlerine daha kolay ulaşılmaktadır? Sorusuna \%78'i evet, \% 22'si hayır de- 
miştir. Devlet hastanelerine randevu alınarak gidilmesi ile sağlık hizmetlerinin kalitesi arttırılmıştır? Sorusuna \% 66'sı evet, \% 64'ü hayır demiştir. Devlet hastanelerine randevu alınarak gidildiği için doktorlar sağlık sorunlarıma daha fazla zaman ayırmaktadır, sorusuna $\% 45$ 'i evet, $\% 55$ hayır demiştir.

Tablo 2. Çalışmaya Katılan Hemşirelerin Yaş Değişkeni ile Hastane Değerlendirme Kriterleri Arasındaki İlişkiler

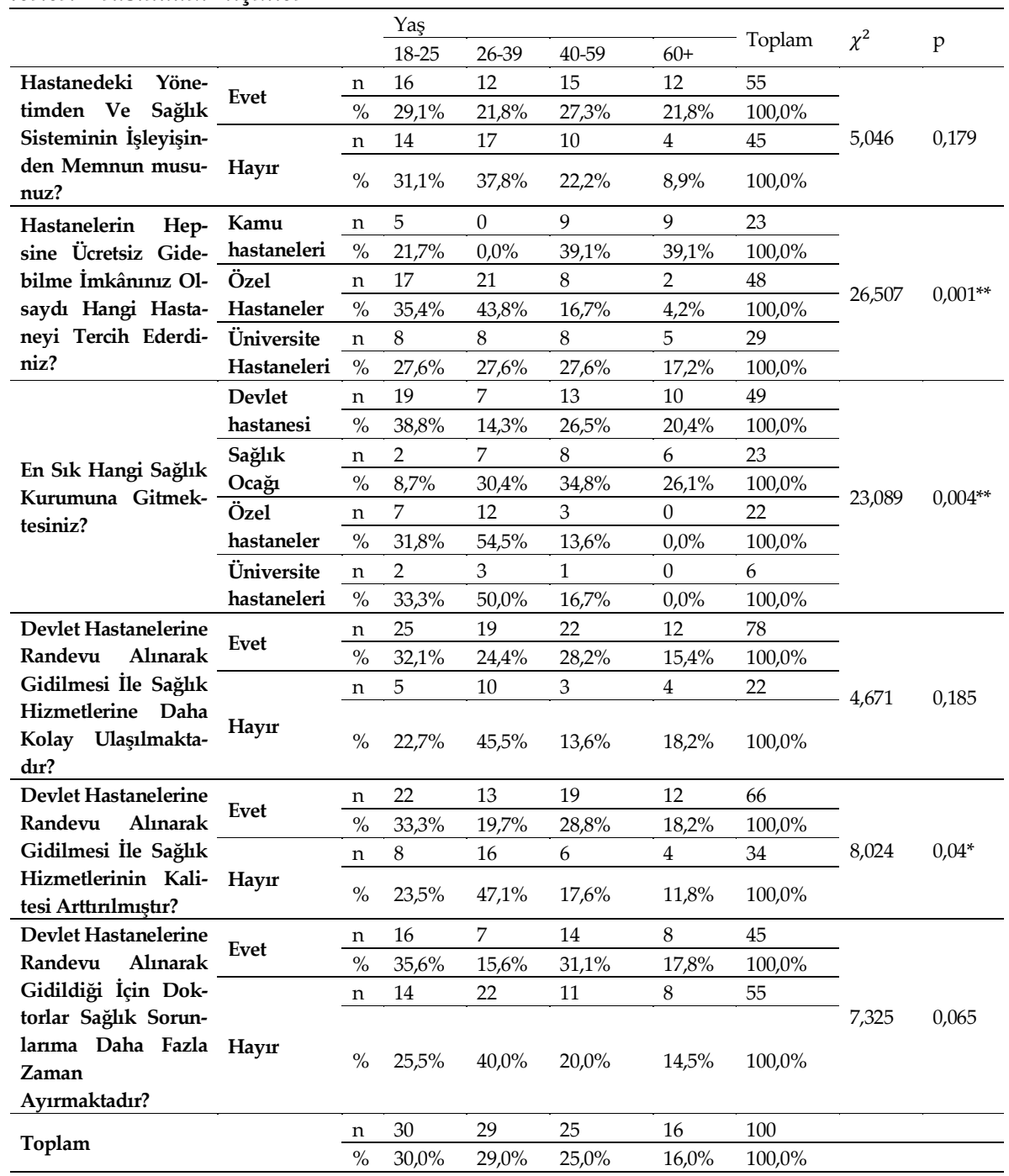

${ }^{*} \mathrm{p}<0,05,{ }^{* *} \mathrm{p}<0,01$ 
Yaş değişkeni ile hastane değerlendirme kriterleri arasındaki ilişkilere bakıldığında 'hastanedeki yönetimden ve sağlık sisteminin işleyişinden memnun musunuz?' sorusuna \%29,1 oranıyla en çok evet cevabı veren kişiler 1825 yaş aralığıdır. En çok hayır cevabı verenler \%37,8 oranıyla 26-39 yaş aralığidır.

'Hastanelerin hepsine ücretsiz gidebilme imkânını olsaydı hangi hastaneyi tercih ederdiniz?' sorusuna $40-59$ ve $60+$ yaş aralığı iki grup $\% 39,1$ oranıyla kamu hastaneleri cevabını vermiştir.

Özel hastaneleri \%43,8 oranıyla en çok tercih eden yaş aralığ $26-39$ 'dur. 18-25, 26-39, 40-59 yaş aralığının üniversite hastanelerini \%27,6 oranıyla tercih etmiştirler.

'En sık hangi sağlık kurumuna gitmektesiniz?' sorusuna devlet hastanesini en çok tercih edenlerin yaş aralığı 18-25 aralığıdır. Sağlık ocağını en çok tercih edenler \%34,8 ile 40-59 yaş aralığı, özel hastaneleri \%54,5 en çok tercih eden 26-39 yaş aralığı, üniversite hastanelerini \%50 ile en çok tercih eden 2639 yaş aralığıdır.

Devlet hastanelerine randevu alınarak gidilmesi ile sağlık hizmetlerine daha kolay ulaşılmaktadır? sorusuna \%78'i evet, \% 22 hayır demiştir.

Devlet hastanelerine randevu alınarak gidilmesi ile sağlık hizmetlerinin kalitesi arttırılmıştır? sorusuna \%66'sı evet, \%34'ü hayır demiştir.

'Devlet hastanelerine randevu alınarak gidildiği için doktorlar sağlık sorunlarıma daha fazla zaman ayırmaktadır.' Sorusuna \%45 evet, \%55'i hayır demiştir.

Tablo 3. Çalışmaya Katılan Hemşirelerin Cinsiyet Değişkeni ile Hastane Değerlendirme Kriterleri Arasindaki İlişkiler

\begin{tabular}{|c|c|c|c|c|c|c|c|}
\hline & & & \multicolumn{2}{|c|}{ Cinsiyet } & \multirow{2}{*}{ Toplam } & \multirow{2}{*}{$\chi^{2}$} & \multirow[b]{2}{*}{$\mathrm{p}$} \\
\hline & & & Kadın & Erkek & & & \\
\hline \multirow{4}{*}{$\begin{array}{l}\text { Hastanedeki Yönetimden Ve } \\
\text { Sağlık Sisteminin İşleyişinden } \\
\text { Memnun musunuz? }\end{array}$} & \multirow{2}{*}{ Evet } & $\mathrm{n}$ & 35 & 20 & 55 & \multirow{4}{*}{5,551} & \multirow{4}{*}{0,018} \\
\hline & & $\%$ & $63,6 \%$ & $36,4 \%$ & $100,0 \%$ & & \\
\hline & \multirow{2}{*}{ Hayır } & $\mathrm{n}$ & 18 & 27 & 45 & & \\
\hline & & $\%$ & $40,0 \%$ & $60,0 \%$ & $100,0 \%$ & & \\
\hline \multirow{6}{*}{$\begin{array}{l}\text { Hastanelerin Hepsine Ücretsiz } \\
\text { Gidebilme İmkânınız Olsaydı } \\
\text { Hangi Hastaneyi Tercih Ederdi- } \\
\text { niz? }\end{array}$} & \multirow{2}{*}{$\begin{array}{l}\text { Kamu } \\
\text { hastaneleri }\end{array}$} & $\mathrm{n}$ & 11 & 12 & 23 & \multirow{6}{*}{0,631} & \multirow{6}{*}{0,727} \\
\hline & & $\%$ & $47,8 \%$ & $52,2 \%$ & $100,0 \%$ & & \\
\hline & Özel & $\mathrm{n}$ & 25 & 23 & 48 & & \\
\hline & Hastaneler & $\%$ & $52,1 \%$ & $47,9 \%$ & $100,0 \%$ & & \\
\hline & \multirow{2}{*}{$\begin{array}{l}\text { Üniversite } \\
\text { Hastaneleri }\end{array}$} & $\mathrm{n}$ & 17 & 12 & 29 & & \\
\hline & & $\%$ & $58,6 \%$ & $41,4 \%$ & $100,0 \%$ & & \\
\hline \multirow{3}{*}{$\begin{array}{l}\text { En Sık Hangi Sağlık Kurumuna } \\
\text { Gitmektesiniz? }\end{array}$} & Devlet & $\mathrm{n}$ & 27 & 22 & 49 & \multirow{3}{*}{3,668} & \multirow{3}{*}{0,305} \\
\hline & hastanesi & $\%$ & $55,1 \%$ & $44,9 \%$ & $100,0 \%$ & & \\
\hline & Sağlık & $\mathrm{n}$ & 15 & 8 & 23 & & \\
\hline
\end{tabular}




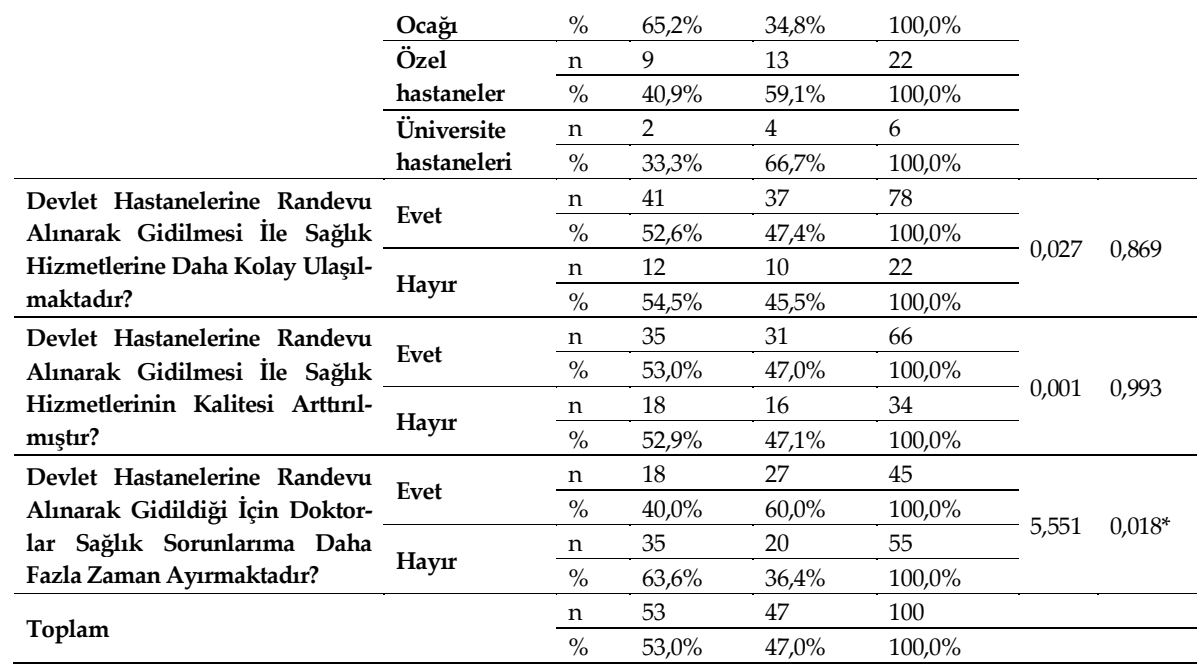

${ }^{*} \mathrm{p}<0,05$

Cinsiyet değişkeni ile hastane değerlendirme kriterleri arasındaki ilişkiler incelendiğinde Hastanedeki yönetimden ve sağlık sisteminin işleyişinden memnun musunuz? sorusuna kadınların \%63,6 evet, \%40'1 hayır demiştir. Erkeklerin \%36,4 evet, \%60'1 hayır demiştir.

Hastanelerin hepsine ücretsiz gidebilme imkânınız olsaydı hangi hastaneyi tercih ederdiniz? sorusuna kadınların $\% 47,8$ kamu hastanelerini, \%52,1'i özel hastaneleri, \%58,6'sı üniversite hastanelerini tercih etmişlerdir. Erkeklerin $\% 52,2^{\prime}$ si kamu hastanelerini, $\% 47,9^{\prime}$ u özel hastaneleri, $\% 41,4^{\prime}$ ü üniversite hastanelerini tercih etmişlerdir.

'En sık hangi sağlık kurumuna gitmektesiniz?' sorusuna kadınların \%55,1 devlet hastaneleri, \%65,2 sağlık ocağını, \%40,9'u özel hastaneleri, \%33,3’ü üniversite hastaneleri cevabını vermişlerdir. Erkeklerin \%44,9'u devlet hastaneleri, \%34,8'i sağlık ocağını, \%59,1'i özel hastaneleri, \%66,7'si üniversite hastaneleri demiştir. En çok tercih edilen sağlık kurumu sağlık ocaklarıdır.

'Devlet hastanelerine randevu alınarak gidilmesi ile sağlık hizmetlerine daha kolay ulaşılmaktadır?' sorusuna kadınların \%52,6's1 evet, \%54,5'i hayır demiştir. Erkeklerin \%47,4'ü evet, \%45,5 hayır demiştir. Genel olarak randevu alınarak gidilmesinin sağlık hizmetlerine kolay ulaşımda fayda sağlamadığ görülmektedir. 
'Devlet hastanelerine randevu alınarak gidilmesi ile sağlık hizmetlerinin kalitesi arttırılmıştır?' sorusuna kadınların \%53'ü evet, \%47'si hayır demiştir. Erkeklerin \%52,9' u evet, \%47,1 hayır demiştir.

'Devlet hastanelerine randevu alınarak gidildiği için doktorlar sağlık sorunlarıma daha fazla zaman ayırmaktadır.' sorusuna kadınların \%40'1 evet, \%63,6'sı hayır demiştir. Erkeklerin \%60' 1 evet, \%36,4'ü hayır demiştir. Kadınlar, randevu alınarak hastaneye gidildiğinde doktorların gereken zamanı ayırmadığı cevabını vererek aldıkları sağlık hizmetinden memnuniyetsizliklerini göstermişlerdir.

Tablo 4: Çalışmaya Katılan Hemşirelerin Öğrenim Durumu Değişkeni ile Hastane Değerlendirme Kriterleri Arasındaki İlişkiler

\begin{tabular}{|c|c|c|c|c|c|c|c|c|c|c|}
\hline & & & \multicolumn{5}{|c|}{ Öğrenim Durumu } & \multirow[b]{2}{*}{ Toplam } & \multirow[b]{2}{*}{$\chi^{2}$} & \multirow[b]{2}{*}{$\mathrm{p}$} \\
\hline & & & İlkokul & $\begin{array}{l}\text { Ortao- } \\
\text { kul }\end{array}$ & $\begin{array}{l}\text { Lise } \\
\text { Mezunu }\end{array}$ & $\begin{array}{l}\text { Yükseko- } \\
\text { kul } \\
\text { /Fakülte }\end{array}$ & $\begin{array}{l}\text { Yüksek } \\
\text { Lisans } \\
\text { /Doktora }\end{array}$ & & & \\
\hline \multirow{4}{*}{$\begin{array}{l}\text { Hastane- } \\
\text { deki Yöne- } \\
\text { timden Ve } \\
\text { Sağlık Sis- } \\
\text { teminin İş- } \\
\text { leyişinden } \\
\text { Memnun } \\
\text { musunuz? }\end{array}$} & \multirow{2}{*}{ Evet } & $\mathrm{n}$ & 14 & 10 & 16 & 15 & 0 & 55 & \multirow[b]{4}{*}{20,164} & \multirow[b]{4}{*}{$0,001^{\text {** }}$} \\
\hline & & $\%$ & $25,5 \%$ & $18,2 \%$ & $29,1 \%$ & $27,3 \%$ & $0,0 \%$ & $100,0 \%$ & & \\
\hline & & $\mathrm{n}$ & 1 & 7 & 8 & 25 & 4 & 45 & & \\
\hline & Hayır & $\%$ & $2,2 \%$ & $15,6 \%$ & $17,8 \%$ & $55,6 \%$ & $8,9 \%$ & $100,0 \%$ & & \\
\hline \multirow{6}{*}{$\begin{array}{l}\text { Hastanele- } \\
\text { rin Hepsine } \\
\text { Ücretsiz } \\
\text { Gidebilme } \\
\text { İmkânınız } \\
\text { Olsaydı } \\
\text { Hangi Has- } \\
\text { taneyi Ter- } \\
\text { cih Ederdi- } \\
\text { niz? }\end{array}$} & Kamu & $\mathrm{n}$ & 5 & 8 & 6 & 4 & 0 & 23 & \multirow{6}{*}{19,518} & \multirow{6}{*}{$0,011^{\text {*** }}$} \\
\hline & $\begin{array}{l}\text { hasta- } \\
\text { neleri }\end{array}$ & $\%$ & $21,7 \%$ & $34,8 \%$ & $26,1 \%$ & $17,4 \%$ & $0,0 \%$ & $100,0 \%$ & & \\
\hline & Özel & $\mathrm{n}$ & 9 & 6 & 10 & 19 & 4 & 48 & & \\
\hline & $\begin{array}{l}\text { Hasta- } \\
\text { neler }\end{array}$ & $\%$ & $18,8 \%$ & $12,5 \%$ & $20,8 \%$ & $39,6 \%$ & $8,3 \%$ & $100,0 \%$ & & \\
\hline & Üni- & $\mathrm{n}$ & 1 & 3 & 8 & 17 & 0 & 29 & & \\
\hline & $\begin{array}{l}\text { versite } \\
\text { Hasta- } \\
\text { neleri }\end{array}$ & $\%$ & $3,4 \%$ & $10,3 \%$ & $27,6 \%$ & $58,6 \%$ & $0,0 \%$ & $100,0 \%$ & & \\
\hline \multirow{8}{*}{$\begin{array}{l}\text { En Sık } \\
\text { Hangi Sağ- } \\
\text { lı Kuru- } \\
\text { muna Git- } \\
\text { mektesi- } \\
\text { niz? }\end{array}$} & Devlet & $\mathrm{n}$ & 12 & 8 & 13 & 14 & 2 & 49 & \multirow{8}{*}{17,437} & \multirow{8}{*}{0,129} \\
\hline & $\begin{array}{l}\text { hasta- } \\
\text { nesi }\end{array}$ & $\%$ & $24,5 \%$ & $16,3 \%$ & $26,5 \%$ & $28,6 \%$ & $4,1 \%$ & $100,0 \%$ & & \\
\hline & Sağlık & $\mathrm{n}$ & 1 & 5 & 4 & 13 & 0 & 23 & & \\
\hline & Ocağı & $\%$ & $4,3 \%$ & $21,7 \%$ & $17,4 \%$ & $56,5 \%$ & $0,0 \%$ & $100,0 \%$ & & \\
\hline & Özel & $\mathrm{n}$ & 2 & 2 & 5 & 12 & 1 & 22 & & \\
\hline & $\begin{array}{l}\text { hasta- } \\
\text { neler }\end{array}$ & $\%$ & $9,1 \%$ & $9,1 \%$ & $22,7 \%$ & $54,5 \%$ & $4,5 \%$ & $100,0 \%$ & & \\
\hline & Üni- & $\mathrm{n}$ & 0 & 2 & 2 & 1 & 1 & 6 & & \\
\hline & $\begin{array}{l}\text { versite } \\
\text { hasta- } \\
\text { neleri }\end{array}$ & $\%$ & $0,0 \%$ & $33,3 \%$ & $33,3 \%$ & $16,7 \%$ & $16,7 \%$ & $100,0 \%$ & & \\
\hline \multirow{4}{*}{$\begin{array}{l}\text { Devlet Has- } \\
\text { tanelerine } \\
\text { Randevu } \\
\text { Alınarak }\end{array}$} & Fyet & $\mathrm{n}$ & 14 & 12 & 17 & 32 & 3 & 78 & \multirow{4}{*}{3,432} & \multirow{4}{*}{0,488} \\
\hline & Evet & $\%$ & $17,9 \%$ & $15,4 \%$ & $21,8 \%$ & $41,0 \%$ & $3,8 \%$ & $100,0 \%$ & & \\
\hline & & $\mathrm{n}$ & 1 & 5 & 7 & 8 & 1 & 22 & & \\
\hline & Hayır & $\%$ & $4,5 \%$ & $22,7 \%$ & $31,8 \%$ & $36,4 \%$ & $4,5 \%$ & $100,0 \%$ & & \\
\hline
\end{tabular}




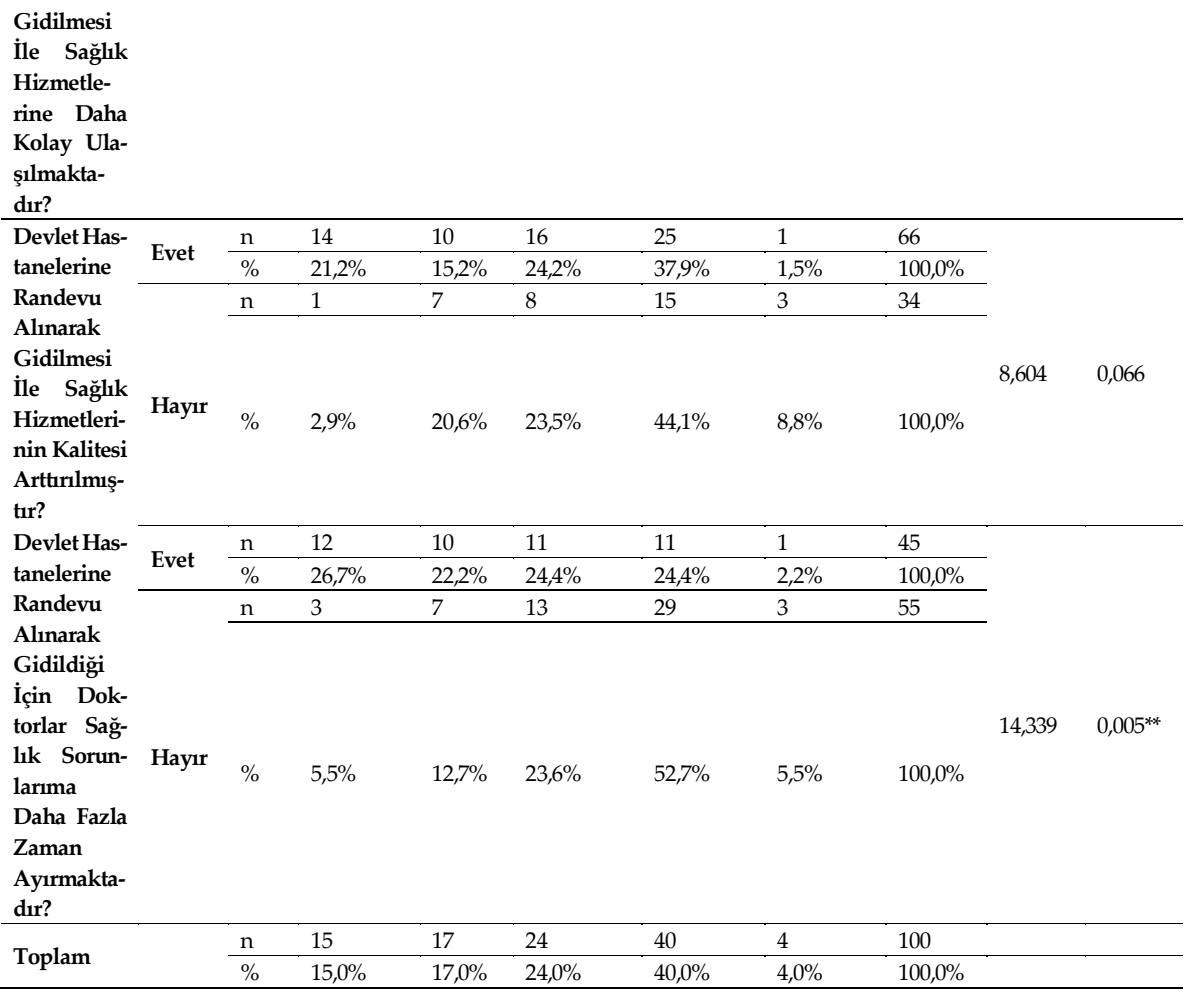

${ }^{* *} \mathrm{p}<0,01$

Öğrenim durumu değişkeni ile hastane değerlendirme kriterleri arasındaki ilişkiler incelendiğinde 'Hastanedeki yönetimden ve sağlık sisteminin işleyişinden memnun musunuz?' sorusuna en yüksek $\% 29,1$ oranıyla lise mezunları evet, \%55,6 oranıyla yüksekokul/fakülte mezunları hayır demiştir.

‘Hastanelerin hepsine ücretsiz gidebilme imkânınız olsaydı hangi hastaneyi tercih ederdiniz?' sorusuna verilen cevaplardaki en yüksek yüzdeler; ortaokul mezunlarının \%34,8'i kamu hastaneleri, özel hastaneleri yüksekokul mezunlarının \%39,6's1, üniversite hastanelerini \%58,6 oranıla yükseko$\mathrm{kul} /$ fakülte mezunları tercih etmektedir.

'En sık hangi sağlık kurumuna gitmektesiniz?' sorusuna lise mezunlarının $\% 26,5$ 'i devlet hastanesi, yüksekokul/fakülte mezunlarının \%56,5'i sağlık ocağı, ortaokul ve lise mezunlarının her ikisi de \%33,3 oranıyla üniversite hastanelerine gitmekte olduklarını söylemiş̧lerdir. 
'Devlet hastanelerine randevu alınarak gidilmesi ile sağlık hizmetlerine daha kolay ulaşılmaktadır?' sorusuna yüksekokul/fakülte mezunlarının \%41'i evet, \%36,4'ü hayır demiştir.

\section{Sonuç}

Sağlıkla ilgili yapılan anketler hem sağlık hizmet kalitesini hem yönetimin kalitesini ölçmek için kullanılan önemli göstergelerdendir. Geri bildirimi ancak bu şekilde sağlanır. Sağlık hizmeti sunan personelin ve yönetim düzeyinde çalışan personelin, tüm kişilik özellikleri hasta memnuniyeti üzerinde önemli rol oynamaktadır (Taşlıyan ve Akyüz, 2010:65). Yaş, cinsiyet, öğrenim durumu kriterleri baz alınarak hemşirelere 6 soru sorulmuştur. Hastanedeki yönetimden ve sağ lık sisteminin işleyişinden memnun musunuz? sorusuna, sorusuna \% 55 evet demiştir. Cinsiyet değişkeninde, kadınların \%63,6 evet, \%40' 1 hayır demiştir. Öğrenim durumu değişkeninde, \%55,6 oranıyla yüksekokul/fakülte mezunları hayır demiştir. Hastanelerin hepsine ücretsiz gidebilme imkânınız olsaydı hangi hastaneyi tercih ederdiniz sorusuna, \% 48 gibi büyük bir çoğunluk özel hastane demiştir. Cinsiyet ve öğrenim durumu değişkenlerinde, yüksekokul/fakülte mezunlarının büyük çoğunluğu üniversite hastanelerini tercih etmektedir. En sık hangi sağlık kurumuna gidildiği sorusuna, \% 49'u devlet hastanesi, yaş değişkeninde, özel hastaneleri $\% 54,5$ en çok tercih eden 26-39 yaş aralığı, üniversite hastanelerini \%50 ile en çok tercih eden 26-39 yaş aralığıdır. Cinsiyet değişkeninde, sorusuna kadınların büyük çoğunluğu devlet hastaneleri ve sağlık ocağını, erkeklerin büyük çoğunluğu ise özel hastaneleri ve üniversite hastaneleri demiştir. Öğrenim durumu değişkeninde, yüksekokul/fakülte mezunlarının $\% 56,5^{\prime}$ i sağlık ocağı, ortaokul ve lise mezunlarının her ikisi de $\% 33,3$ oranıyla üniversite hastanelerine gitmekte olduklarını söylemişlerdir. Devlet hastanelerine randevu alınarak gidilmesi ile sağlık hizmetlerine daha kolay ulaşılıp-ulaşılmadığı sorusuna, \%78'i evet demiştir. Devlet hastanelerine randevu alınarak gidilmesi ile sağlık hizmetlerinin kalitesi arttırmış mıdır? Sorusuna, \% 66'sı evet, diğer değişkenlerde de oran yüksektir. Devlet hastanelerine randevu alınarak gidildiğinde doktorların sağlık sorunlarına daha fazla zaman ayırıp-ayırmadığı sorusuna, \% 45'i evet, \% 55 hayır demiştir. Kadınların, \%40'1 evet, erkeklerin \%60'1 evet demiştir. Kadınlar, randevu alınarak hastaneye gidildiğinde 
doktorların gereken zamanı ayırmadığı cevabını vererek aldıkları sağlık hizmetinden memnuniyetsizliklerini göstermişlerdir. Öğrenim durumu değişkeninde yüksekokul/fakülte mezunlarının \%41'i evet, \%36,4'ü hayır demiştir. Genel olarak bakıldığında, büyük çoğunluk hastane yönetiminden ve işleyişinden, aldıkları sağlık hizmetlerinden memnun olduğu görülmektedir. Sağlık kurumlarında verimliliği ve hasta memnuniyetini artırmak, maliyeti azaltmak, sunulan hizmetin kalitesini artırmak için bilgi teknolojilerinin kullanımı yaygınlaştırılmalıdır. Özellikle, zaman kavramının önemli olduğu bu kurumlarda veriye erişimi hızlandırmak, veri paylaşımı ve süreçlerin daha etkili bir şekilde yönetimi için sağlık bilişim sistemleri her sağlık kurumunda kullanılmalıdır (Çiriş Yıldız vd., 2020:484). Sağlık bilişim uygulamalarının yaygınlaşabilmesi için bu konularla ilgili gelişmeler sağlanmalı ve uygun önlemler alınmalıdır. Bunun yanında hasta memnuniyetini artırmak için sağlık bilişiminin değerini ortaya çıkarmak ve hekimler tarafından sıklıkla kullanılan güvenilir bir sistem haline getirmek için teknik olarak uygun, tıbbi olarak geçerli, geri ödenebilir ve kurumsal olarak desteklenen uygulamalar geliştirilmelidir (Demirhan ve Güler, 2011:20). 


\title{
EXTENDED ABSTRACT
}

\section{Patient Satisfaction In Health Care Management: An Example Of Public Hospital}

\author{
Elçin Güven \\ Ersin İnanç Mali Müşavirlik A.Ş
}

The assessment of patient satisfaction comprises the expectations of patients and their relatives, evaluation of feedbacks and also the evaluated results (Dinç vd., 2009, p.93). This survey study comprises health care management, patient satisfaction and the questionnare study conducted in a public hospital in Province of Kirklareli. The method of the study; While preparing the Questionnaire Form, documents obtained as a result of literature review and made use of within this regard, Emre KOL who is a doctorate student at the University of Anatolia, Social Sciences Institute, Department of Labour Economics and Industrial Relations and his research study namely "The Transformation Experienced in Health Care Services in Turkey: A Research on Low Income Groups" Necessary modifications are fulfilled and made use of while preparing the final sketch of the Questionnaire Form. The Questionnaire Form was adapted to the goals of this study and the survey was conducted at a public hospital by asking 100 nurses 6 questions face to face. The necessary permission was obtained from the Health Directorate of Kırklareli Province for the duration of 19-29 February 2019. The obtained data was processed and assessed by using the programme of SPPS 25 (IBM Corporation which was released in 2017 INM SPSS Statistics for Windows, Version 25.0 Armonk, NY: IBM Corp). Frequency values and percentage values were utilized within the variables. Categorical data were analysed by using Ki Square Test and Fisher's Exact Test. The "Monte Carlo Simulation Model was adopted and utilized due to the fact that the expected values were smaller than $20 \%$. For the significance level of Tests $p<0,05$ and $p<0,01$ values were accepted. 
Result of the Survey: It has been observed that those questionnaires adopted and conducted have already proved that the questionnaire conducted on issues related to health care services revealed significant results both to measure the quality of health care services and the quality of the method so they are important indicators within this respect. It has been observed that both the attitudes and personality characteristics of the health care staff and also the personnel who work at the level of management play an important role on patients' satisfaction (Taşliyan, Akyüz, 2010:65). Nurses were asked six questions by taking their age, gender and their educational background into consideration. $55 \%$ of the nurses replied the question "Are you satisfied with the hospital management and the operation of the health system? by saying "Yes" In the variable of gender, $63,6 \%$ of the women nurses said "Yes" and $40 \%$ said "No". As in the variable of educational background, $55.6 \%$ of those graduates of higher Education Faculty replied the same question "No". When they were asked the question "If you were allowed to go hospitals free of charge, would you prefer the public hospitals or private hospitals, $48 \%$ of them, the majority answered the question as private hospitals. By taking into their gender and educational background, majority of the participants of higher education and faculty graduates prefer university hospitals. The question "Which health care institution do you often go to? was answered like this: $49 \%$ of them preferred public hospitals but in the variable of gender, 54.5 of them who prefer private hospitals were between the range of 26-39 years old. Those who mostly prefer university hospitals are between the range of 26-39 years old. When it comes to the variable of gender, most of the women preferred public hospitals and primary health care centres whereas the majority of men answered the same question by saying private hospitals and university hospitals. When it comes to the variable of educational background $56.5 \%$ of those higher education and Faculty graduates preferred primary health care centres but the graduates of secondary schools and senior high schools both of them said that $33.3 \%$ of them go to university hospitals. The question whether it is easier to reach the health care services on the condition that one gets an appointment prior to the medical examination, $78 \%$ of them answered this question as "Yes". When the question like this was asked, "Did going to public hospitals after arranging a health care appointment increase the quality of 
health care services, $66 \%$ of the participants answered the question by saying "Yes". The rate is much higher in the other variables. The question whether the doctors spare more time for their patients or not if the patients go to hospitals after making an appointment, $45 \%$ of them said "Yes" but $55 \%$ of them said "No". $40 \%$ of women answered this question by saying "Yes". But $60 \%$ of men said "No". The women participants said that doctors did not spare enough time for their patients even if they go to hospital after making an appointment and thus they expressed their dissatisfaction from the health care services. When it comes to the variable of the educational background, $41 \%$ of those higher education and faculty graduates said $41 \%$ but $36.4 \%$ of them said "No". Utilization of information technologies should be popularised in order to increase the quality of health care services, patients' satisfaction and fidelity of the health care institutions, to reduce health care costs, especially in those health care institutions where the concept of time is crucial, it is essential to accelerate the data access, data sharing and all sorts of necessary measures must be taken in order to handle such procedures which necessitate establishing departments of information technologies and effective information processing systems in all health care institutions (Çiriş Yıldız, 2020, p.484). Innovative approaches must be encouraged, information applications must be popularized in health care institutions by following new inventions and developments in order to stay updated and suitable measures must be taken within this regard. Besides, technically compatible, effective, reliable and frequently used systems which are utilized by doctors should be provided in order to increase patient satisfaction by all means by taking affordable systems into consideration and applications must be improved and supported institutionally (Demirhan ve Güler, 2011, p.20). 


\section{Kaynakça / References}

Akçakant, T., Çarıkç, H. (2019). Performansa dayah ücret sistemi ve sağhk kurumlarnnda uygulanması. 1.Baskı, İstanbul: Hiper Yayın.

Akdaş, A., Sur, H., Şişman, N., Gemlik, N. (2008). İdari Görevi Bulunan Hekimlerin Sağllk Yönetimine Bakış Açları. Sağlık Düşüncesi ve Tip Kültürü̈ Platformu Dergisi, 2(5). http://www.sdplatform.com/Dergi/157/Idari-gorevi-bulunan-hekimlerin-saglik-yonetimine-bakis-acilari adresinden erişilmiştir.

Can, A., ve İbicioğlu, H. (2008). Yönetim ve Yöneticilik Yönünden Üniversite Hastanelerinin Değerlendirilmesi. Süleyman Demirel Üniversitesi İktisadi ve İdari Bilimler Fakültesi Dergisi, 13(3), 253-275.

Çağlayaner, H. (2008). Avrupa'da ve Türkiye'de sağlık politikaları. Türkiye Aile Hekimlï̆i Dergisi, 12(1), 55-55.

Çimen, M. (2010). Sağllk Yönetimi ve Sağllk Yönetim Eğitimi. Acıbadem Üniversitesi Sağlık Bilimleri Dergisi, 1(3), 136-139.

Çiriş, Yıldız, C., Başıbüyük, M., ve Yıldırım, D. (2020). Klinik Karar Destek 483 Sistemlerinin Hemşirelikte Kullanım. İnönü Üniversitesi Sağlık Hizmetleri Meslek Yüksekokulu Dergisi, 8(2), 483-495.

Demirhan, A., Güler İ., (2011). Bilişim ve Sağlı. Bilişim Teknolojileri Dergisi, 4(3), 13-20.

Dinç, D., Ünalan, P., Topsever, P., ve Özyavaş, S. (2009). Hasta Memnuniyeti ve Yönetim Sistemi: Çözüm Ortağı Hekim. Türk Aile Hekimi Dergisi, 13(2), 93-98.

Faezipour, M., Ferreira, S., (2013). A System Dynamics Perspective of Patient Satisfaction in Healthcare, Procedia Computer Science, 16, 148-156.

Gezergün, A., Şahin, B., Tengilimoğlu, D., Demir, C.,ve Bayer, E. (2006). Hastaların Bakış Açssıla Hekim-Hasta İlişkisi ve İletişimi; Bir Eğitim Hastanesi Örneği. Anadolu Üniversitesi Sosyal Bilimler Dergisi, 6(1), 129-144.

Ginter, P., Duncan, J., Swayne, L. (2018). Strategic Management of Health Care Organizations. 8th Edition, Wiley\& Sons Inc., New Jersey.

Hawthorne, G., Sansonic, J., Hayesb L., Marosszekyf N., Sansoni E., (2014). Measuring Patient Satisfaction with Health Care Treatment Using the Short Assessment of Patient Satisfaction Measure Delivered Superior and Robust Satisfaction Estimates, Journal of Clinical Epidemiology 67, 527-537.

Hayran, O. (2012). Sağlk Yönetimi Yazlları. 2. Baskı, Ankara: Sage Yayınallk, https://www.researchgate.net/publication/305656763, adresinden erişilmiştir.

Kara, B. (2018). Türkiye' de sağlık alanında yapılan stratejik yönetim ile ilgili araştırma sonuçlarının hemşirelik perspektifinden değerlendirilmesi. Sağlkve Sosyal Refah Araştırmaları Dergisi, 1(1), 51-59. 
Kılıç, T., Topuz, R. (2015). Hastalarla İletişimin, Hasta Memnuniyetine Etkisi: Özel, Devlet ve Üniversite Hastanesi Karşılaştırılması. Sağlıkta Performans Kalite Dergisi, (9), 78-95.

Linnander, E., Mantopoulos, J., Nikole Allen N., Nembhard, I., , Bradley, E. (2017). Professionalizing Healthcare Management: A Descriptive Case Study. Int J Health Policy Manag, 6(10), 555-560.

Luo, L., Gao, J., (2017). Inaugural Editorial to Journal of Hospital Management and Health Policy, J Hosp Manag Health Policy, 1:1.

Mutlu, A., Işık, K. (2012). Sağlık Ekonomisine Giriş. 1. Baskı, Bursa: Ekin Basım Yayın Dağtım.

Stewart, J., Wolvaardt, G., (2019). Hospital Management and Health Policy -a South African Perspective, J Hosp Manag Health Policy, 3(14), http://dx.doi.org/10.21037/jhmhp.2019.06.01.

Stacy, J. P., ve Adam, L. S., (2019). Improving Health and Health Care Efficiency Through Risk Management, J Hosp Manag Health Policy, 3(9) http://dx.doi.org/10.21037/jhmhp.2019.04.0.

Taşlıyan, M., ve Akyüz, M. (2010). Sağlık Hizmetlerinde Hasta Memnuniyet Araştırması: Malatya Devlet Hastanesi'nde Bir Alan Çalışması. KMÜ Sosyal ve Ekonomik Araştırmalar Dergisi, 12 (19), 61-66.

Tengilimoğlu, D., Işık, O., ve Akbolat, M. (2012). Sağhlk İşletmeleri Yönetimi. 5.Baskı, Ankara: Nobel Yayınevi.

Thiedke, C. (2007). What Do We Really Know About Patient Satisfaction. Family Practice Management, 14(1), 33-36.

Tükel, B., Acuner, A. M., Önder, Ö.R., ve Üzgül, A., (2004). Ankara Üniversitesi İbn-i Sina Hastanesinde Yatan Hasta Memnuniyeti (Genel Cerrahi Anabilim Dalı Örneği), Ankara Üniversitesi Tıp Fakültesi Mecmuasl, 57(4),205-214.

Ürün, Ş. (2019). Sağlık Yönetiminde Performans Değerlendirilmesi. (Yayınlanmamış Yüksek Lisans Tezi). Kırıkkale Üniversitesi Sosyal Bilimler Enstitüsü, Kırıkkale.

Yorulmaz, M. (2015). Türkiye'deki Sağhlk Yönetiminin Mevcut Durumu ve Geleceğine Dair Nitel Bir Çalışma. (Yayınlanmamış Doktora Tezi). Süleyman Demirel Üniversitesi, Sosyal Bilimler Enstitüsü, Isparta.

Yılmaz, M. (2001). Sağlıkta Bakım Kalitesinin Bir Ölçütü: Hasta Memnuniyeti. Cumhuriyet Üniversitesi Hemşirelik Yüksekokulu Dergisi, 5(2), 69-74.

Xesfingi, S., ve Vozikis, A., (2016). Patient Satisfaction With the Healthcare System: Assessing The Impact of Socioeconomic and Healthcare Provision Factors, BMC Health Services Research, 16(94), DOI 10.1186/s12913-016-1327-4. 
Zaim, H., ve Tarm, M., (2010). Hasta Memnuniyeti: Kamu Hastaneleri Üzerine Bir Alan Araştrrmasi, Sosyal Siyaset Konferanslan, 59(2), 1-24.

Zavare, M., Abdullah, M., Hassan S., Said S.,ve Kamali, M. (2010). Patient Satisfaction: Evaluating Nursing Care for Patients Hospitalized with Cancer in Tehran Teaching Hospitals Iran. Global Journal of Health Science, 2(1), 117-126.

\section{Kaynakça Bilgisi / Citation Information}

Güven, E. (2021). Sağlık yönetiminde hasta memnuniyeti: Bir Devlet Hastanesi örneği. OPUS-Uluslararası Toplum Araştırmaları Dergisi, 17(37), 4873-4893. DOI: 10.26466/opus.872579 